\title{
THE PYRAMID TRACT IN THE RED SQUIRREL (SCIURUS HUDSONIUS LOQUAX) AND CHIP- MUNK (TAMIAS STRIATUS LYSTERI)
}

\author{
SUTHERLAND SIMPSON \\ From the Physiological Laboratory, Medical College, Cornell University \\ THIRTY-SEVEN FIGURES
}

\section{INTROODUCTION}

The nerve fibers which form the pyramid tract take origin from the large pyramidal cells of Betz ('09) in the cerebral motor cortex. Entering the corona radiata they converge and pass caudalward through the internal capsule, crusta, pontine bundles and anterior pyramid until the lower part of the medulla oblongata is reached. The tract, in its passage downward, gives off fibers or collaterals to the optic thalamus, substantia nigra, nuclei pontis of the same side, and to the nuclei of the cranial motor nerves mainly of the opposite side. The positions occupied by the pyramid tract at these different levels are similar in all the mammalian orders that have been investigated, with slight variations, until the lower part of the bulb is reached, but beyond this, where it passes into the spinal cord, great differences are found to exist.

In man and the anthropoid apes, at the decussation of the pyramids the fibers divide into three bundles; most of them cross the middle line and enter the dorsal portion of the lateral column of the opposite side, forming the crossed pyramid tract of the cord. A second group of fibers, much less numerous than the first, turn away from the median raphé on the same side, without crossing, and take up a position in the lateral column corresponding to that of the crossed pyramid tract of the opposite side; this is termed the direct lateral pyramid tract. A third group continue downward from the pyramid into the cord, 
running along the margin of the ventral longitudinal fissure, forming the direct ventral pyramid tract otherwise known as the bundle of Türck. This last can be followed to about the middle of the thoracic region. It is said to be wanting in all mammals below the anthropoid apes; such, however, is not the case, since it is present as a well-marked tract in the porcupine (Erethizon dorsatus, Linn.) and to some extent in the raccoon (Procyon lotor, Linn.), as shown by Simpson ('12).

In the monkey, cat, dog and rabbit the same subdivision takes place at the decussation as in man, except that the direct ventral pyramid tract is absent.

The few species of ungulates that have been examined show that the cortico-spinal fibers of the tract are practically absent and those that do reach the cord cannot be followed beyond the upper cervical segments. Ziehen ('00), in the sheep, says that they decussate, some passing into the dorsal and some into the lateral columns. Dexler and Margulies ('06), in the sheep and goat found that the decussation is not complete; most of the fibers cross and pass into the lateral column of the opposite side; some, however, remain in the ventral column of the same side. King ('11), in the sheep, found also an incomplete decussation; the crossed fibers passed into the lateral column of the opposite side, the direct fibers into the corresponding column of the same side. None could be traced beyond the first cervical segment. Bischoff ('00), in the pig and deer, was unable to say whether the crossed fibers pass into the lateral or the dorsal column.

All are agreed, at any rate, with regard to the ungulates, that the fibers entering the cord are extremely scanty and terminate early.

The insectivora and chiroptera-hedgehog, mole, bat-show similarly an almost complete absence of cortico-spinal fibers, and the very few that do enter the cord end in the first cervical segment. Whether the decussation is complete, partial or entirely absent is still an open question: Bischoff ('00), Ziehen ('99), Kotzenberg ('99), Obersteiner ('03), Edinger ('11), Van der Vloet ('06), Dräseke ('03), Merzbacher and Spielmeyer ('03), and Hatschek ('03). 
In the monotremes and marsupials the fibers are said to decussate into the dorsal columns. Ziehen ('99) found it to be so in the ring-tailed phalanger (Pseudochirus peregrinus). In another species, the koala (Phascolarctus cinereus), he was unable to say whether the fibers, after crossing, pass into the dorsal or lateral column. Edinger ('11) describes complete decussation into the dorsal column in one of the marsupials (Halmaturus giganteus).

The rodents form a large order and comparatively few species have been examined, but here there is a distinct decussation of the pyramids in the lower part of the medulla oblongata, the crossed fibers passing into the dorsal columns. There is one notable exception, however, and that is the Leporidae, including the rabbits and hares. In this family the fibers, after decussating, pass into the lateral column. In the rabbit the crossing is not complete; a few fibers can be traced into the lateral column of the same side. The pyramid tract in this animal, therefore, appears to agree in every respect with that in the cat, dog, and monkey, except that its cortico-spinal fibers are more scanty.

In the rat the pyramid tract was found by Stieda ('69) to decussate into the posterior column, and this has been confirmed by Spitzka ('86), Goldstein ('03), Van der Vloet ('06), King ('10) and Ranson ('13). Most of these observers believe that the decussation is complete.

A complete crossing of the cortico-spinal fibers into the posterior column has also been described by Kotzenberg ('99) in the marmot, and by Bechterew ('90), Wallenberg (cited by Goldstein '03) and Reveley and Simpson ('09) in the guinea-pig.

In the Canadian porcupine (Erethizon dorsatus, Linn.) the condition is unique (Simpson '12). The fibers of the anterior pyramid, on entering the cord, divide into four fasciculi, two crossed and two direct. Of the crossed fibers, the greater number pass into the dorsal column (crossed dorsal tract), but a few can be followed into the lateral column (crossed lateral tract). A very considerable number of fibers remain uncrossed and are continued into the spinal cord, forming a comparatively large and compact bundle in the ventral column extending along 
the margin of the ventral longitudinal fissure (direct ventral tract). Some fibers are also found in the dorsal column of the same side, forming a direct dorsal tract.

In the brief summary of previous work on the subject given above, no mention has been made of the methods employed, but in the great majority of cases these were faulty, consisting as they did in the examination of serial sections from normal histological preparations. Particularly has this procedure been adopted in the case of the smaller rodents and insectivors, where the difficulty of operating on the living animal is considerable.

In this relation it should be kept clearly in mind that only two methods are available for tracing the paths of fiber bundles in the central nervous system, namely, the embryological method of Flechsig and the Wallerian method of secondary degeneration. The latter, when followed by Marchi staining, is always to be preferred. As Edinger truly says "Ein echter Tractus corticospinalis ist nur durch Degenerationsversuche zu erkennen. Diese fehlen noch für allermeisten Säuger."

Granted that in serial sections through the decussation in normal preparations the fibers can be traced into one or other of the columns of the spinal cord, it is begging the question to say that these same fibers have their origin in the cerebral motor cortex. They may have some other source and may have joined the tract at a lower level, in which case they will not belong to the pyramidal system and will certainly not be cortico-spinal fibers. Again, where the degeneration method is not used, it is impossible to say whether the decussation is partial or complete. Take as an example the case of the cat, dog, or monkey, where there is a crossed lateral and also a direct lateral tract in the cord. When the cortical lesion is unilateral only one pyramidal system undergoes degeneration and at the decussation, if the Marchi method has been used, it is plainly seen that while most of the fibers decussate into the opposite lateral column, some pass into the corresponding column of the same side without crossing the raphé. If both pyramids were degenerated, or if the fibers were traced in normal preparations, the presence of this direct tract would 
certainly be overlooked since it would be masked by the much larger crossed tract which occupies the same position in the cord.

Nowhere in the literature are to be found entirely satisfactory descriptions of the position of the pyramid tract in the brain and spinal cord in the lower orders of mammals. These are confined, for the most part, to the character of the decussation and do not deal with the topographical relationships at the different levels. It seemed desirable, therefore, to investigate further the course of this important tract by the Marchi method in such of the smaller rodents as could be obtained in this country, and the present paper gives the results as found in two closely allied species, namely, the red squirrel and the chipmunk.

\section{PRESENT INVESTIGATION}

In three red squirrels (Sciurus hudsonius loquax) and three chipmunks (Tamias striatus lysteri), the motor cortex of the left cerebral hemisphere was successfully removed, the operation, in each case being performed under ether anesthesia. After exposing the brain the motor area was located by electrical stimulation but it was found impossible to delimit the area with any degree of accuracy on account of the small size of the animal. It was difficult to get exposure close up to the middle line since the dura mater is very thin and the great longitudinal sinus easily ruptured. After the motor area had been located a shallow incision was made around it with a tenotomy knife and the cortex scraped away with a sharp spade within the limits of this incision. The part of the area extending along the margin of the longitudinal fissure was 'under cut' so as to divide all the nerve fibers coming from it but it was not entirely removed for the reason given above, namely, the risk of hemorrhage from the longitudinal sinus.

The animals were kept under observation for periods varying from thirteen to sixteen days after operation; they were then killed by coal gas, the brain and cord removed and placed in 3 per cent potassium bichromate solution. After hardening for three weeks in this solution, with frequent changing, the tissue 
was cut into slices from 2 to $3 \mathrm{~mm}$. thick and placed in Marchi's fluid made up according to the formula of Van Gehuchten ('06) as follows:

Osmic acid, 1 per cent........................... part

Potassium bichromate, 3 per cent ................... parts

In this solution they were allowed to remain for three weeks. Before being sliced up, photographs of the brain were taken, in each case, to show the position of the lesion.

In Marchi staining it is essential that a large excess of the fluid be used. The pieces of tissue while in the fluid, should be kept in tightly stoppered bottles in a dark and cool room in order to prevent the evaporation of the very volatile osmic acid and its decomposition by the action of light.

The original fluid employed by Marchi consisted of 1 per cent osmic acid one part, Muller's fluid two parts, and in this the tissue was kept for ten days after ten days previous hardening in Muller's fluid. It is claimed, however, that better penetration is secured by using the weaker solution and allowing it to act for a longer time; this I believe to be the case. Further, at the end of the staining process the fluid should not be thrown away; it may be used over and over again with the best results, all that is necessary being the addition of some fresh osmic acid and a small quantity of concentrated solution of potassium bichromate.

Several modifications of this method have been introduced from time to time, for example, by Orr ('00), Vassale ('96), Busch ('98) and others, but in my experience the original Marchi fluid, as used by Van Gehuchten, in its more dilute form, is better than any other. If due attention is paid to the details mentioned above, Marchi staining seldom fails to give good results.

The survival-time after operations is also an important consideration. According to Lange ('00) the optimum time comes between the tenth and fourteenth days. No doubt this will depend, to some extent, on the species of animal used. Most observers are inclined to allow a longer interval than fourteen days. Lange believes that the best results are obtained from adult animals. He fixes his tissue in a mixture of 10 per cent formalin 
and Muller's fluid for the first two or three days and then transfers it to pure Muller's fluid or 3 per cent potassium bichromate solution, changing several times. He also prefers the stronger solution for staining-osmic acid one part, Muller's fluid two parts. In my experience formalin fixation gives uncertain results.

After removal from the Marchi fluid the pieces were washed for several hours in running water, then placed in 75 per cent alcohol, carried up the alcohol-xylene-paraffin series, and imbedded and cut in paraffin. In some cases celloidin was used as the imbedding material.

The entire brain from the mesencephalon to the lower end of the medulla oblongata, including the first cervical segment of the cord, was cut into serial sections, all of which were mounted. This gave series which were not quite continuous, however, since there was always some unavoidable loss in trimming the surfaces of the pieces into which the brain had been originally divided, prior to immersion in the Marchi fluid. Sections were also mounted from each segment of the spinal cord.

\section{RESLLTS OBTAINED}

\section{Red squirrel}

Since the lesion was practically the same in all cases (fig. 1), it will be sufficient to describe in detail the results obtained in one individual of each species. As a matter of fact, it was found that the areas of degeneration at corresponding levels agreed closely in all the animals although some slight differences exist, particularly in the region of the decussation. All the figures refer to the same individual and were drawn from the preparations with the help of a Gage projection apparatus.

Transverse section of mesencephalon through anterior corpora quadrigemina (fig. 2). At the level of the exit of the third nerve the crusta shows degeneration over the entire area of its transverse section, but the lateral and mesial extremities contain fewer fibers than the middle portions. The gray matter of the substantia nigra contains many transversely cut fibers immediately 
behind the crusta; these do not appear to be running dorsalward into the tegmentum, as they are frequently observed to do in the cat and other animals at this level. Their course is cephalo-caudal, and they probably represent straggling bundles detached from the main mass of the tract.

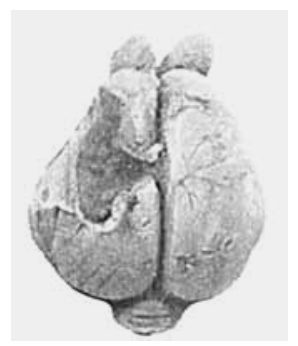

Fig. 1 Brain of red squirrel, dorsal view, showing position of lesion in left cerebral hemisphere. Mengnified $\frac{1}{1}$.

Transverse section near junction of mid-brain and pons through posterior corpora quadrigemina (fig. 3). The tract is now compacted into a single oval-shaped bundle lying just behind the superficial transverse fibers of the pons. Its long diameter extends from before backward and outward. This area contains a large number of degenerated fibers scattered uniformly over its entire surface; none can be seen leaving the bundle on any of its aspects.

Transverse section through middle of pons (fig. 4). The outline of the tract is still more or less oval with a slight projection at the inner angle. The bundle is single and compact, not broken up by the transverse pontine fibers as is the case in the cat, dog and monkey, for example; the black dots are very numerous and are scattered over the whole area. Fine degeneration is very abundant amongst the cells of the nuclei pontis on the mesial, ventral and lateral aspects of the tract; it fades away towards the middle line and does not extend beyond the raphé. No degenerated fibers are to be seen in the mesial fillet lying behind and internal to the pyramid tract. 

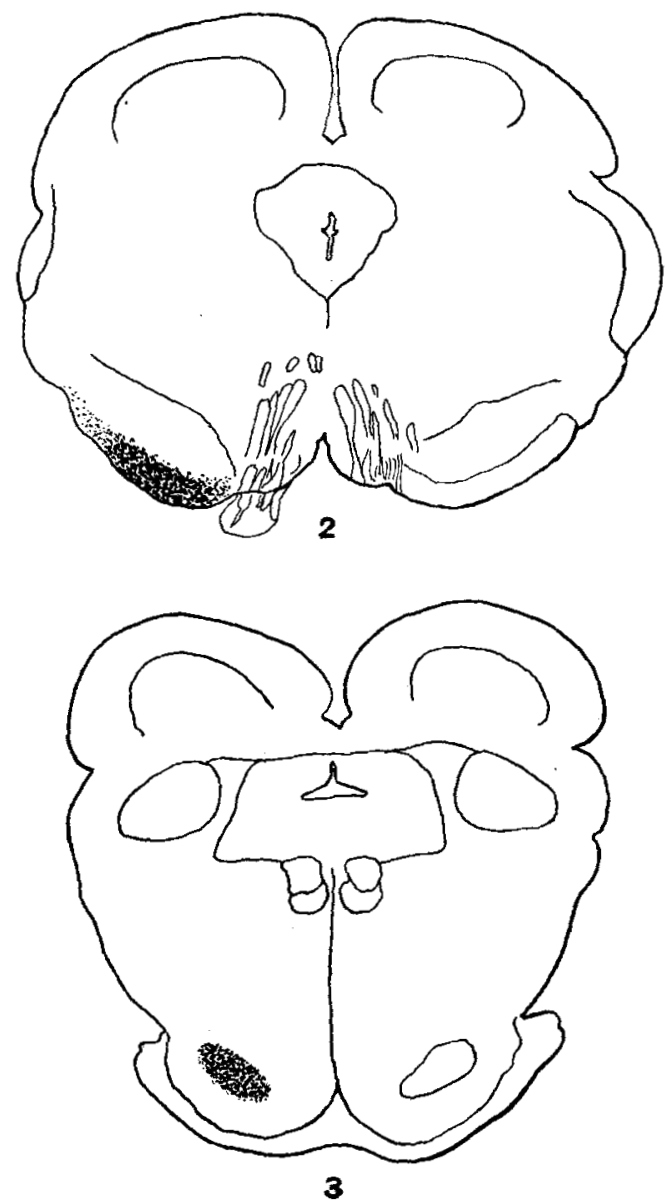

Fig. 2 Transverse section of mesencephalon through anterior corpora quadrigemina. $\times 6$

Fig. 3 Transverse section, near junction of mid-brain and pons. $\times 6$.

Transverse section through junction of pons and medulla oblongata (fig. 5). Sections passing through the seventh nucleus show that the tract has now reached the surface and entered into the formation of the anterior pyramid. Its transverse outline at this level is somewhat lens-shaped, the posterior surface being flattened towards the inner angle and showing an increased curvature towards the outer. The degeneration is abundant and is 

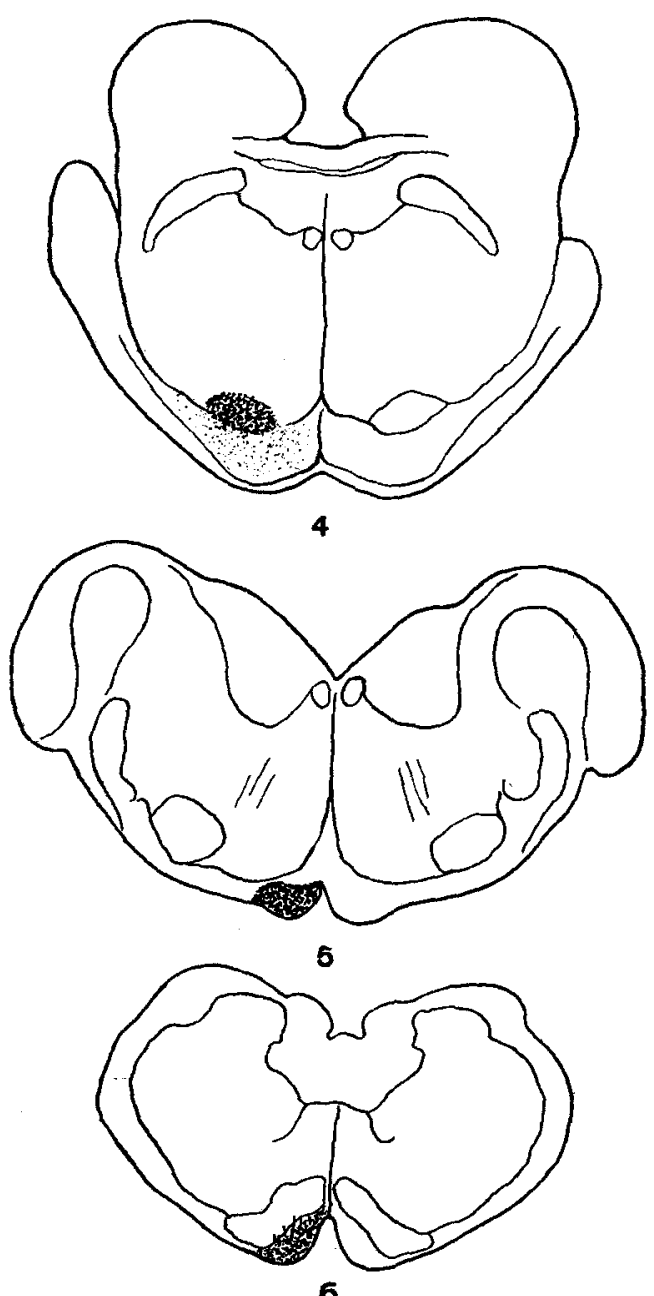

Fig. 4 Transverse section, through middle of pons. $\times 6$.

Fig. 5 Transverse section, near junction of pons and medulla oblongata. $\times 6$. Fig. 6 Transverse section, medulla oblongata. $\times 6$.

scattered uniformly over the whole area. At this level a few fibers from about the middle of the posterior surface can be seen passing backward and inward towards the middle line; none of these, however, reach the raphé, nor can any be followed to the masses of gray matter in the neighborhood. 
Transverse section through medulla oblongata (fig. 6). The section here described passes through the point where the central canal opens into the fourth ventricle. The pyramid has now a plano-convex outline the posterior surface being flattened against the inferior olivary nucleus which lies behind. The long axis runs from the middle line obliquely outward and forward. The whole area is studded with black dots and some fibers can be traced for a very short distance into the olivary nucleus but no indication of fine degeneration is visible in its gray matter. The inner angle of the pyramid is now becoming pointed and some fibers can be seen streaming out from this angle toward the median raphé but none cross as yet at this level.

Transverse section of medulla oblongata through middle of inferior olivary nucleus (fig. 7). The degenerated fibers coming off from the inner angle of the pyramid can now be followed in small bundles across the raphé. They are at first directed backward toward the posterior longitudinal fasciculi in front of the central canal and cross the raphé very obliquely. When almost in contact with these fasciculi they turn suddenly outward and then curve backward through the central gray matter entering the funiculus cuneatus in which they bend caudalward. In their passage through the gray matter they form bow-shaped curves with the concavities toward the central canal. At this level the transversely cut fibers in the funiculus cuneatus form a thin zone lying against the posterior aspect of the gray matter.

Transverse section of medulla oblongata through middle of pyramidal decussation (fig. 8). At a slightly lower level than that outlined in figure 7 , the degenerated fibers are crossing in large numbers and follow practically the same course as already described in the last section. The pyramid itself is now considerably diminished in size and the area of degeneration in the funiculus cuneatus has broadened antero-posteriorly and also moved somewhat towards the middle line but it has not yet invaded the funiculus gracilis.

Transverse section of medulla oblongata through the lower end of inferior olivary nucleus (fig. 9). At this level the decussating fibers are much reduced in number and cross the raphe less obliquely 

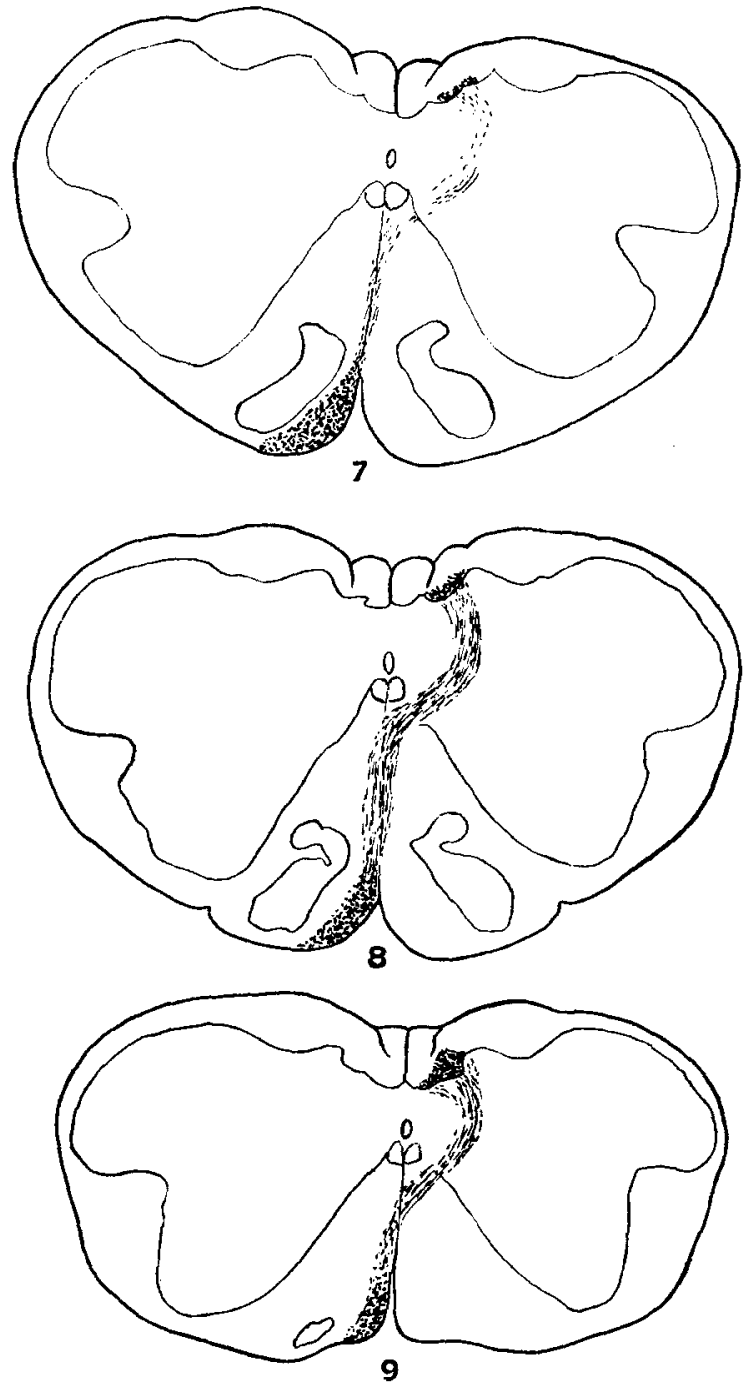

Fig. 7 Transverse section, medulla oblongata through middle of inferior olivary nucleus. $\times 12$.

Fig. 8 Transverse section, medulla oblongata through middle of pyramidal decussation. $\times 12$.

Fig. 9 Transverse section, medulla oblongata through lower end of inferior olivary nuclens. $\times 12$. 
than formerly. The bundles interlace very distinctly with those of the normal pyramid. The pyramid is much reduced in size and the area of degeneration dorsal to the gray matter is correspondingly enlarged. The latter is somewhat triangular in outline and the innermost fibers lie nearer to the middle line but not within the limits of the funiculus gracilis. It will be observed that most of the decussation has taken place above the level of the lower end of the inferior olivary nucleus, and that it is very abrupt, the fibers running almost at right angles to the direction of the pyramid in their passage across the gray matter.

Transverse section through medulla oblongata about the level of the lower extremity of the pyramidal decussation (fig. 10.) What remains of the pyramid is here seen as a narrow zone of degeneration bordering the ventral longitudinal fissure, but most of the fibers have crossed and are to be found in the posterior column where they form a large tract, the sharp inner angle of which reaches almost to the middle line.

Transverse section near junction of spinal cord and medulla oblongata (fig. 11). The decussation is now over and the crossed pyramid tract occupies a comparatively large area in the posterior or dorsal column, in contact with the posterior commissure and extending from the mesial septum laterally into the funiculus cuneatus. No crossed fibers at any level have been observed turning outward through the gray matter to reach the lateral column, nor have any been found to pass into the dorsal or lateral column of the same side. In this animal the decussation appears to be complete and the crossed pyramid tract is confined to the dorsal column.

Transverse section through first cervical segment of spinal cord (fig. 12). The pyramid tract in the cord occupies the same relative position as in the last section. The lateral diameter of the area is somewhat diminished and the antero-posterior diameter increased while the inner extremity is pressed up against the posterior median septum.

Transverse section through second cervical segment (fig. 19). The appearance of the tract is now greatly changed. Its outline is that of an isosceles triangle with the base lying against the 
posterior commissure and the apex directed backward. As compared with that of the first cervical segment the area is somewhat diminished and the degeneration is less dens; from this it would seem that a considerable number of fibers have already disappeared from the tract.

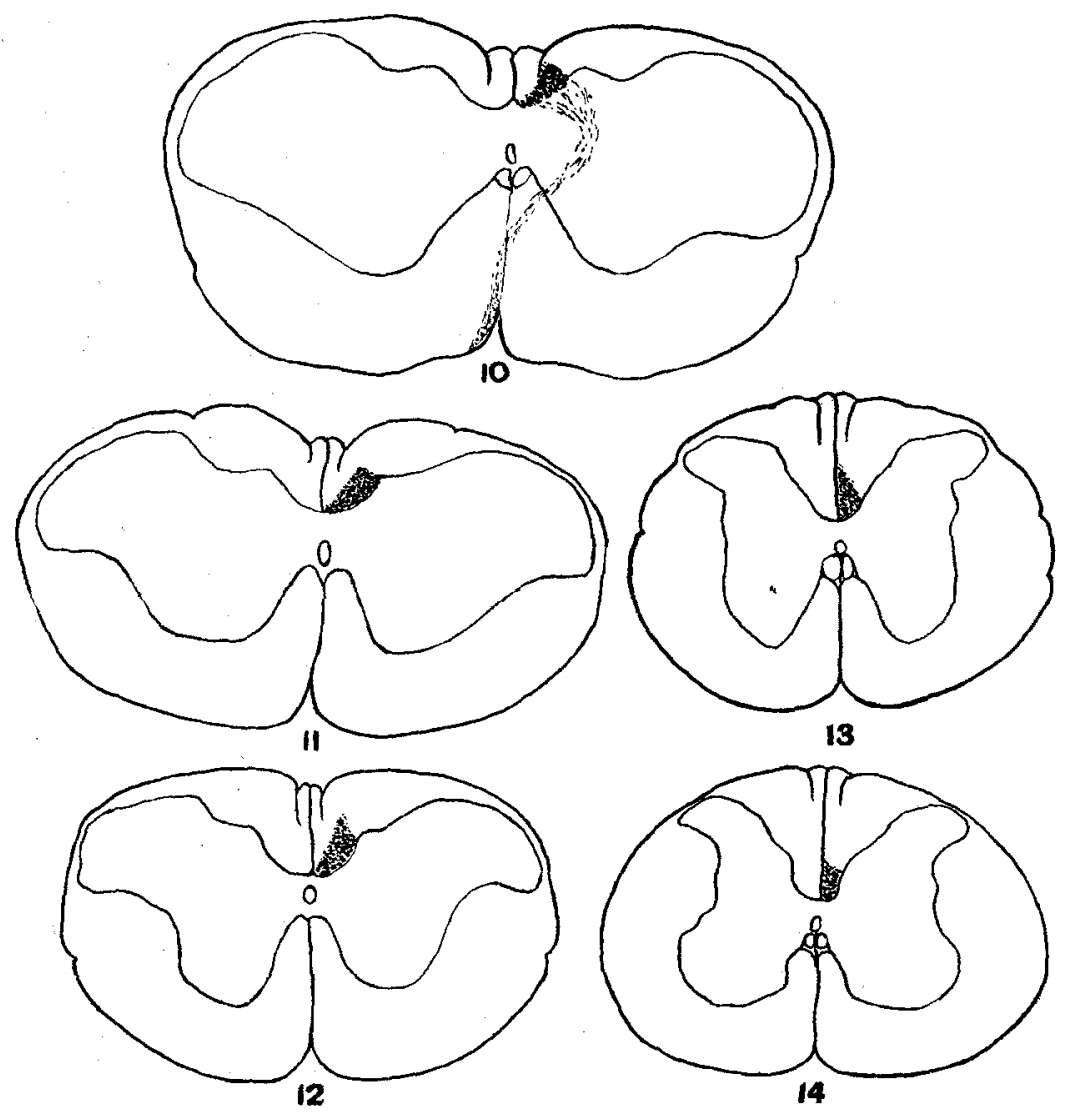

Fig. 1C Transverse section, medulla oblongata near lower limit of pyramidal decussation. $\times 12$.

Fig. 11 Transverse section, near junction of medulla oblongata and spinal cord. $\times 12$.

Fig. 12 Transverse section, first cervical segment of spinal cord. $\times 12$.

Fig. 13 Transverse section, second cervical segment. $\times 12$.

Fig. 14 Transverse section, fourth cervical segment. $\times 12$. 
Transverse section through fourth cervical segment (fig. 14). The tract now occupies the apex of the posterior column being squeezed in between the median septum and the base of the posterior horn. The outline is still triangular but the base at this level is directed backward and the apex forward while the mesial border is considerably shortened.

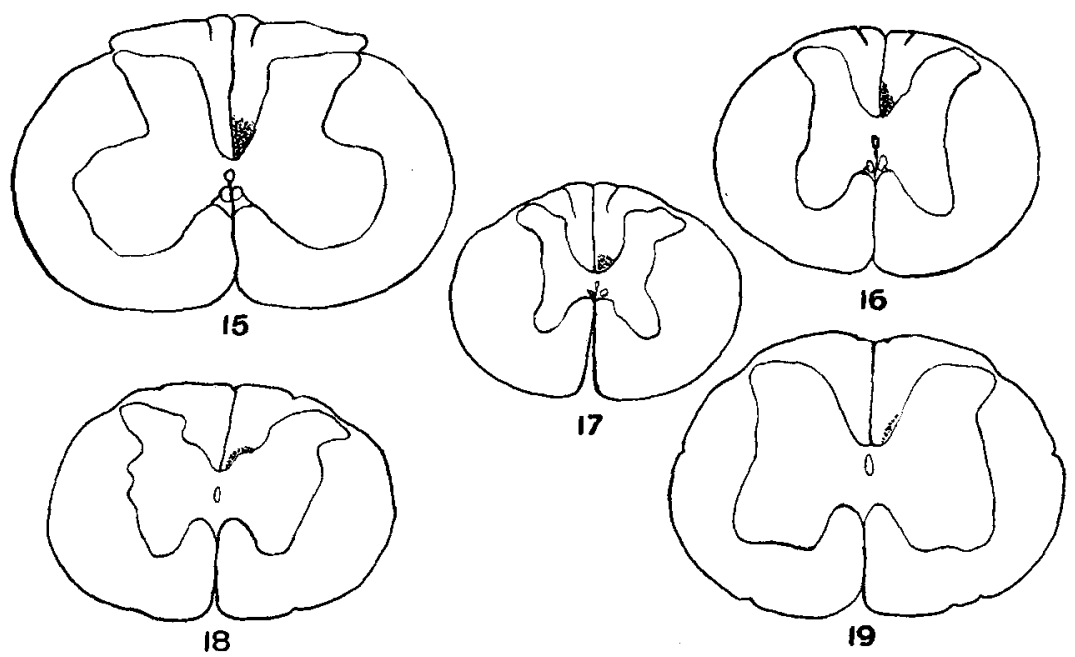

Fig. 15 Transverse section, seventh cervical segment. $\times 12$.

Fig. 16 Transverse section, second thoracic segment. $\times 12$.

Fig. 17 Transverse section, eighth thoracic segment. $\times 12$.

Fig. 18 Transverse section, second lumbar segment. $\times 12$.

Fig. 19 Transverse section, fifth lumbar segment. $\times 12$.

Transverse section through seventh cervical segment (fig. 15). At this level there is little change; the tract is somewhat reduced in size and the degenerated fibers are less numerous.

Transverse section through second thoracic segment (fig. 16.) The outline of the tract here resembles that seen in the second cervical segment, being triangular in form with the base lying against the posterior commissure and the apex pointing backward. Between this and the seventh cervical segment a large number of fibers have disappeared. 
Transverse section through eighth thoracic segment (fig. 1\%). At this level the tract is greatly reduced in size; it occupies a comparatively small area at the apex of the column.

Transverse section through second lumbar segment (fig. 18). The degenerated fibers are now found in close relation to the base of the posterior horn; they have left the middle line and extend along the mesial border of the gray matter, but no fibers have been observed entering the gray matter at this or any other level in the spinal cord.

Transverse section through fifth lumbar segment (fig. 19). All that represents the crossed pyramid tract here are a few scattered fibers lying close to the gray matter. In this particular animal the degeneration cannot be followed farther than this segment, but in one of the three squirrels used in these experiments some fibers are still present in the last sacral segment.

For the squirrel these results agree with those of Goldstein ('03) who found that the decussation in the lower part of the medulla oblongata is complete, all the fibers passing into the posterior columns. With regard to the course of the tract in the spinal cord he gives no details. He was chiefly concerned with the behavior of the fibers at the decussation. For this animal he was the first to use the degeneration method and so to prove that there does exist a cortico-spinal tract.

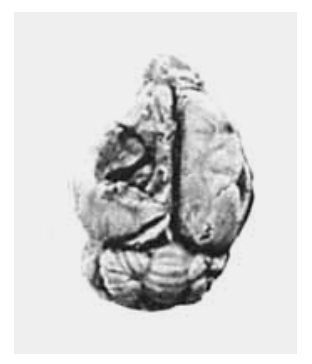

Fig. 20 Brain of chipmunk, dorsal view, showing position of lesion in left cerebral hemisphere. Magnified $\frac{1}{4}$. 


\section{Chipmunk}

In the chipmunk the degeneration is similar to that found in the squirrel in the mid-brain, pons and medulla oblongata until the decussation is reached, so that it will be unnecessary to describe sections above this level. It is confined to the side of the lesion. Of the three animals used, one is selected for description but the results obtained in all are in close agreement. The lesion in the left cerebral hemisphere as it appeared in this animal when the brain was removed is shown in figure 20 .

Transverse section through medulla oblongata near upper limit of decussation of pyramids (fig. 21). The pyramid, at this level, lies ventro-mesial to the inferior olivary nucleus. Its transverse section is oval in outline, pointed at the inner and outer extremities. From the inner angle a few fibers, cut longitudinally, can be seen passing toward the raphe but none as yet reach it; this represents the beginning of the decussation. The degeneration appears to be confined entirely to the left side, that is, to the side of the cortical lesion.

Transverse section of medulla oblongata through pyramidal decussation (fig. 22). The pyramid is still oval-shaped but the direction of its long axis is more dorso-ventral than in the last section. Degenerated fibers are seen crossing the raphé in bundles which interlace with those of the sound pyramid. They curve dorsalward through the gray matter and pass into the funiculus cuneatus in which they turn toward the spinal cord.

Transverse section of medulla oblongata through middle of pyramidal decussation (fig. 23). This section passes through the middle of the decussation; the inferior olivary nucleus is still seen. The degenerated fibers are crossing in large bundles and the pyramid is much reduced in size. A large crossed tract is now present in the funiculus cuneatus and it has moved nearer to the middle line. No fibers, at this or at any other level, turn outward in the gray matter toward the lateral column and none join the bundles of the sound pyramid and pass to the dorsal column of the same side, as they can be seen to do in the porcupine. 


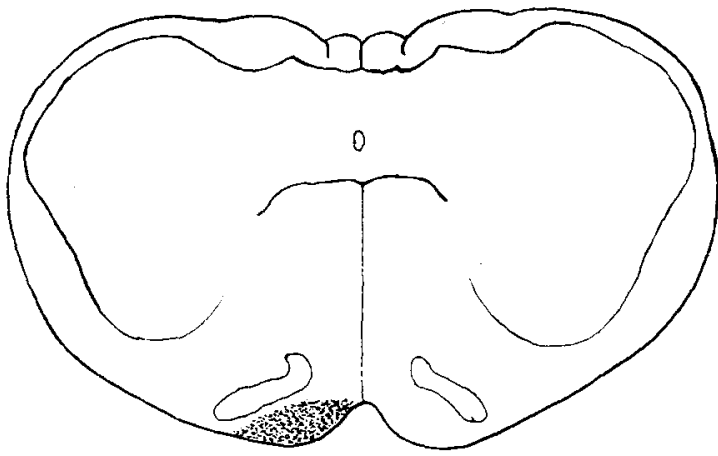

21

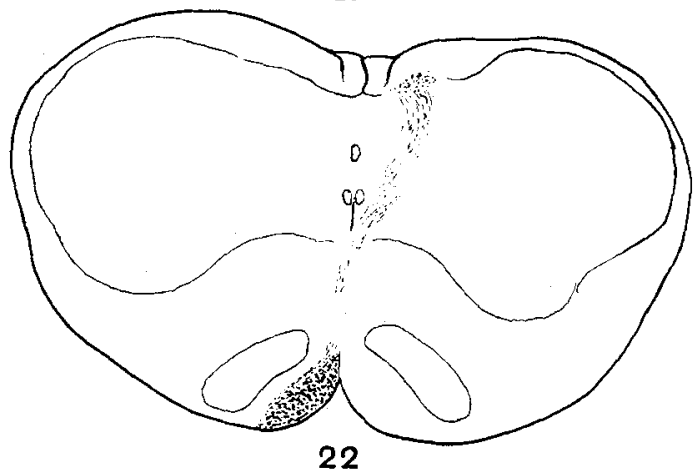

22

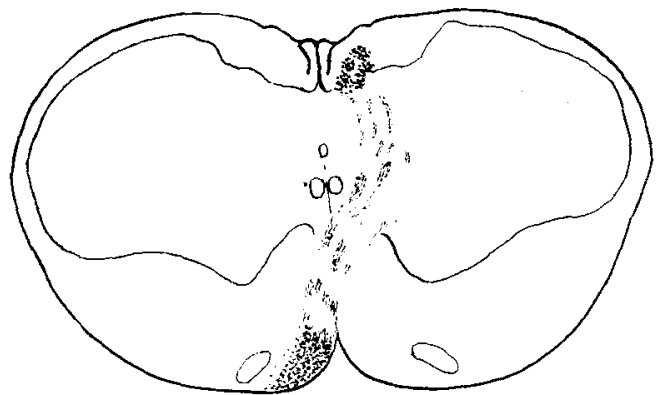

23

Fig. 21 Transverse section, medulla oblongata above decussation of pyramids. $\times 12$.

Fig. 22 Transverse section, medulla oblongata through pyramidal decussation. $\times 12$.

Fig. 23 Transverse section, medulla oblongata through pyramidal decussation. $\times 12$. 
In the chipmunk, as in the squirrel, the decussation appears to be complete.

Transverse section through medulla oblongata just caudal to pyramidal decussation (fig. 24). All the fibers have now crossed and are found in the posterior column cut transversely, where they form the dorsal pyramid tract. It is larger than in the previous sections and has moved nearer to the middle line. At its inner angle two distinct bundles are seen in this section.

Transverse section through cephalic portion of first cervical segment of the spinal cord (fig. 25). This section, passing through the proximal part of the first cervical segment, shows the crossed dorsal tract lying in the posterior column. It is wedge-shaped in outline, with the base lying against the posterior commissure and the apex directed dorsalward. The inner angle now reaches the posterior median septum.

Transverse section through caudal portion of first cervical segment (fig. 26). In the first cervical segment the tract undergoes rapid changes in size and form. Its area in the caudal portion of the segment is somewhat reduced and the degenerated fibers which it contains are not so closely packed as in the last section. It is still triangular in shape but it is narrowed laterally and almost the whole extent of its mesial border lies in contact with the posterior median septum.

Transverse section through second cervical segment (fig. 27). The tract now lies in the angle formed by the median septum with the border of the posterior horn. It is still triangular in outline but the base is directed backwards and the apex forwards.

Transverse section through fourth, sixth and eighth cervical segments ( figs. 28, 29, 30). At these three levels there is little change except in the number of degenerated fibers, which decrease as the thoracic region is approached. The area occupied by the tract in each of these segments is shown in the corresponding figure.

Transverse section through second thoracic segment (fig. 31). The tract is considerably reduced in size, but shows the same general outline and occupies the same position as in the cervical region. 
Transverse section through seventh thoracic segment (fig. 32). In the mid-thoracic region the tract has the same general outline as in the second thoracic segment, but it extends farther dorsalward along the median septum. There is also some reduction in the number of degenerated fibers which it contains.

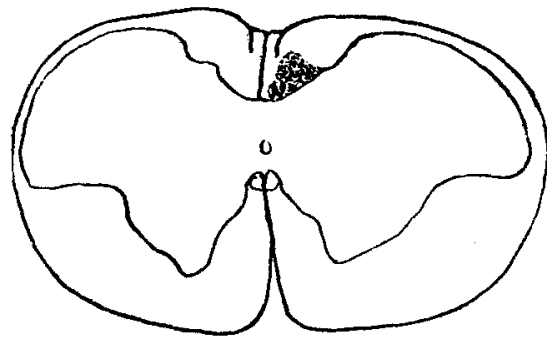

24

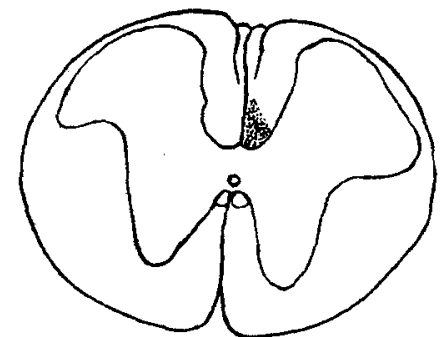

26

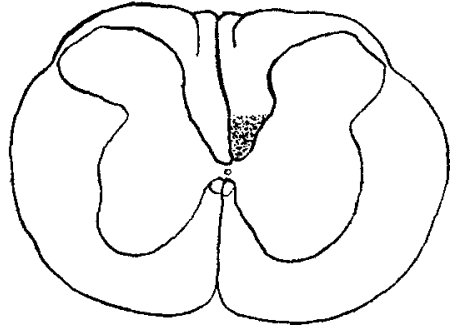

28

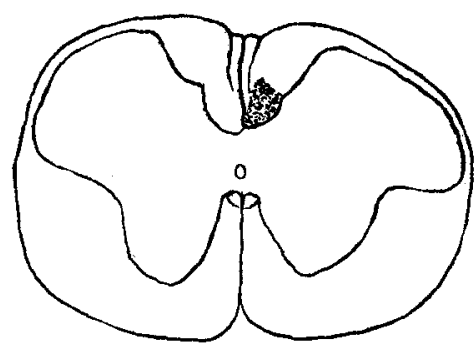

25

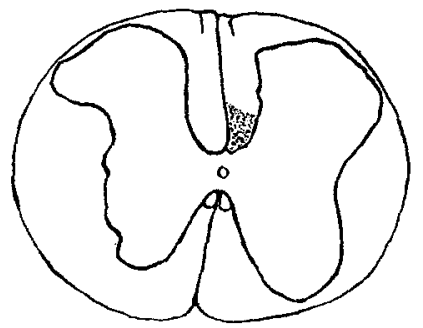

27

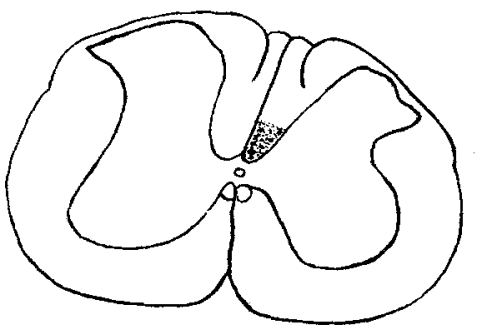

29

Fig. 24 Transverse section, medulla oblongata. $\times 12$.

Fig. 25 Transverse section, upper level of first cervical segment of cord. $\times 12$.

Fig. 26 Transverse section, first cervical segment, lower level. $\times 12$.

Fig. 27 Transverse section, second cervical segment. $\times 12$.

Fig. 28 Transverse section, fourth cervical segment. $\times 12$.

Fig. 29 Transverse section, sixth cervical segment. $\times 12$. 


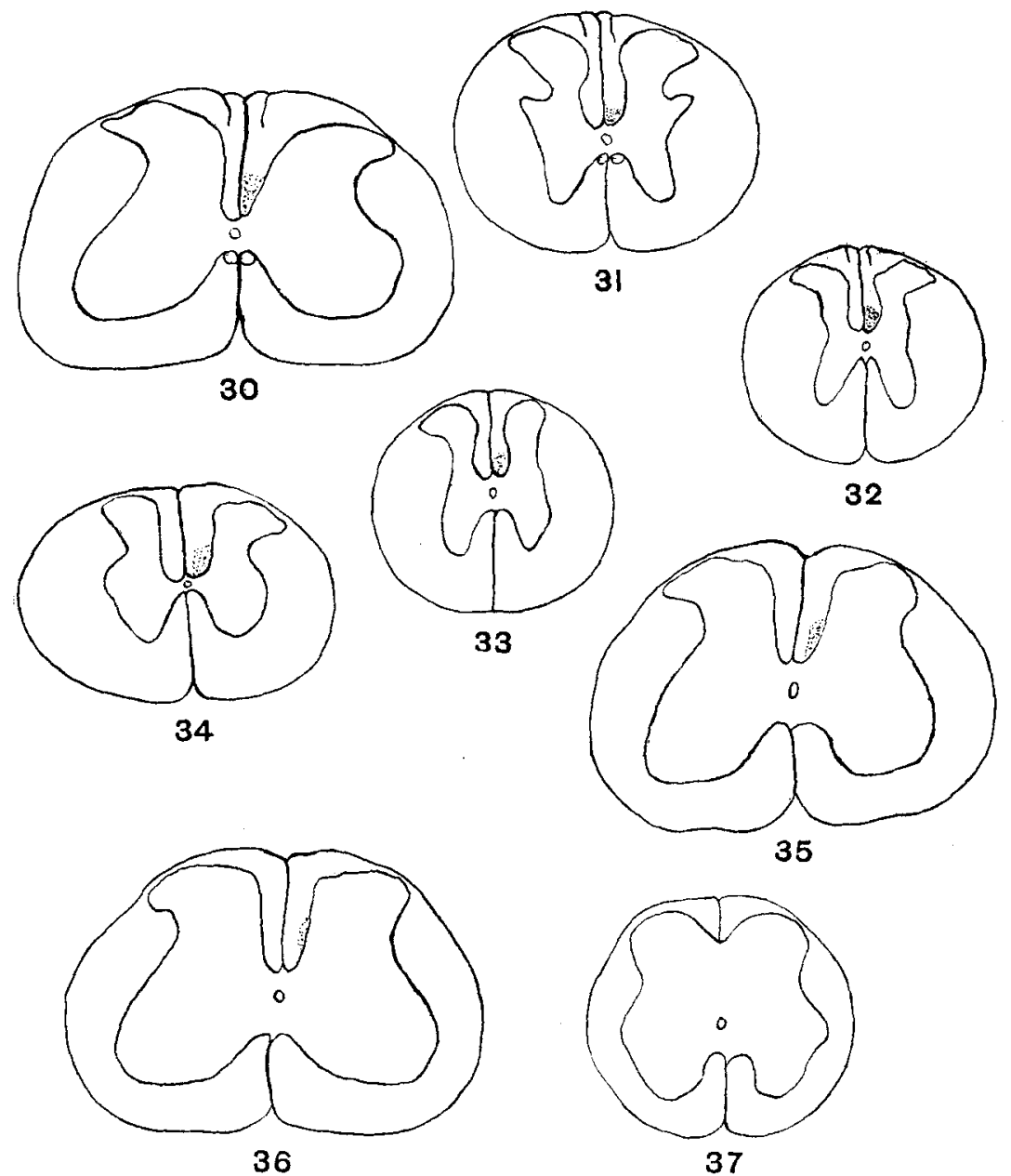

Fig. 30 Transverse section, eighth cervical segment. $\times 12$.

Fig. 31 Transverse section, second thoracic segment. $\times 12$.

Fig. 32 Transverse section, seventh thoracic segment. $\times 12$.

Fig. 33 Transverse section, twelfth thoracic segment. $\times 12$.

Fig. 34 Transverse section, first lumbar segment. $\times 12$.

Fig. 35 Transverse section, third lumbar segment. $\times 12$.

Fig. 36 Transverse section, first sacral segment. $\times 12$.

Fig. 37 Transverse section, fourth sacral segment. $\times 12$. 
Transverse sections through twelfth thoracic and first lumbar segments (figs. 34 and 35). In the twelfth thoracic segment the tract still meets its fellow of the opposite side at the posterior median septum but in the first lumbar segment this is no longer the case; it has now left the septum and is separated from it by a zone of sound fibers, the degenerated area lying against the mesial border of the posterior horn.

Transverse sections through third lumbar and first sacral segments (figs. 35 and 36). At the level of the third lumbar segment the degenerated fibers are greatly reduced in number and form a narrow zone along the ventral part of the mesial border of the posterior horn. In the first sacral segment very few fibers remain.

Transverse section through fourth sacral segment (fig. 37). At this level six or eight degenerated fibers can still be seen in the posterior column.

Comparing the figures at corresponding levels in the medulla oblongata and spinal cord, it will be seen that the distribution of the pyramid tract in the squirrel and chipmunk agrees closely. In both species it is confined to the dorsal column in the spinal cord and there is no trace of a direct tract.

\section{SUMMARY}

The cortical motor areas in the left cerebral hemisphere were extirpated in three red squirrels (Sciurus hudsonius loquax) and three chipmunks (Tamias striatus lysteri) and the resulting degeneration followed by the Marchi method.

The pyramid tract occupies the usual position in the crusta, pons and medulla oblongata until the decussation is reached. Here, in the lower part of the bulb, the fibers cross the middle line abruptly in bundles which interlace with those of the sound side and pass through the gray matter into the funiculus cuneatus where they turn caudalwards to enter the spinal cord and form the crossed pyramid tract. The decussation is complete, no fibers remaining on the same side when the spinal cord is reached. 
There is no sign of a crossed lateral tract.

The dorsal tract can be followed as far as the lower sacral segments.

A considerable number of degenerated fibers disappear in the upper cervical segments of the spinal cord.

\section{BIBLIOGRAPHY}

BeChTEREW, W. 1890 Ueber die verschiedenen Lagen und Dimensionen der Pyramidenbahnen beim Menschen und den Tieren und über das Vorkommen von Fasern in denselben, welche sich durch eine frühere Entwickelung anszeichnen. Neurol. Centralbl., p. 738.

Bischoff, E. 1900 Beitrag zur Anatomie des Igelgehirnes. Anat. Anz., Bd. 18, p. 348 .

Busch, Сн. K. 1898 Ueber eine Färbungsmethode secundärer Degenerationen des Nervensystems mit Osmiumsäure. Neurol. Centralbl., p. 117.

Dexler, H., and Margulies, A. 1906 Ueber die Pyramidenbahn des Schafes und der Ziege. Morphologisches Jahrbuch, Bd. 35, p. 413.

DräsmKe, J. 1903 Zur mikroskopischen Kenntnis der Pyramiden Kreuzung der Chiropteren. Anat. Anz., Bd. 23, p. 449.

Edinger, L. 1911 Bau der nervösen Zentralorgane. Leipzig, 8th Ed. Bd. 1, p. 150.

Goldstern, K. 1903 Zur vergleichenden Anatomie der Pyramidenbahn. Anat. Anz., Bd. 24, p. 451.

Hatschex 1903 Arb. a. d. Neurol. Instit. a. d. wiener Univ., H. 10, p. 48.

Holmes, G. M., ANd MaY, W. PAge 1909 On the exact origin of the pyramidal tracts in man and other mammals. Brain, vol. 32, p. 1 .

KING, JESsIE I. 1910 The cortico-spinal tract of the rat. Anat. Rec., vol. 4, p. 245 .

1911 The pyramid tract and other descending paths in the spinal cord of the sheep. Quar. jour. Exper. Physiol., vol. 4, p. 133.

Kotzenberg. 1889 Untersuchungen über das Rückenmark des Igels. Wiesbaden, p. 19.

de Lange, S. J. 1909 La methode de Marchi. Le Névraxe, vol. 10, p. 115.

Merzbacher, L. und Spielmeyer, W. 1903 Beiträge zur Kenntniss des Fliedermausgehirns besonders der corticomotorischen Bahnen. Neurol. Centralblatt, p. 1050.

Obergteiner, L. 1903 Anleitung beim Studium des Baues der nervösen Zentralorgane, p. 402. 
OrR, David 1900 A method of staining medullated fibres 'en bloc;' and a morification of the Marchi method. Jour. Path. and Bacteriol., p. 387.

Ranson, S. W. 1913 The fasciculus cerebro-spinalis in the albino rat. Amer. Jour. Anat., vol. 14, p. 411.

REveley, IdA L., AND Srmpson, S. 1909 The cortico-spinal tract in the guineapig. Report of British Association, Winnipeg Meeting, p. 645.

Simpson, S. 1912 a The pyramid tract in the Canadian porcupine (Erethizon dorsatus, Linn.). Proc. Soc. Exper. Biol. and Med., vol. 10, p. 5.

$1912 \mathrm{~b}$ The motor cortex and pyramid tract in the raccoon (Procyon lotor, Linn). Proc. Soc. Exper. Biol. and Med., vol. 10, p. 46.

Spitzka, E. C. 1886 The comparative anatomy of the pyramid tract. Jour. Compar. Med. and Surg., vol. 7, p. 46.

STIEDA, L. 1869 Studien über das centrale Nervensystem der Vögel und Säugethiere. Zeitsch. f. wiss. Zoologie, Bd. 19, p. 68.

Van Gehuchten, A. 1906 Système nerveux de l'homme. Louvain, 4th Ed., p. 340 .

VASSALE, A. 1896 Riv. Speriment di Freniatria, p. 790.

$V_{\text {AN DER VLOET }} 1906$ Ueber der Verlauf der Pyramidenbahn bei niederen Säugetieren. Anat. Anz., Bd. 29, p. 113.

Wallenberg, A. 1903 Cited by Goldstein, Anat. Anz., Bd. 24, p. 454.

Zienen, Th. 1899 Zur vergleichenden Anatomie der Pyramidenbahn. Anat, Anz., Bd. 16, p. 446.

1900 Ueber der Pyramidenkreuzung des Schafes. Anat. Anz., Bd. 17, p. 237 . 